\title{
Corrosion Behavior of 304 Stainless Steel Exposed to a Simulated Salt Lake Atmosphere
}

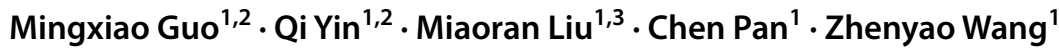

Received: 28 November 2019 / Revised: 13 January 2020 / Published online: 16 March 2020

(c) The Chinese Society for Metals (CSM) and Springer-Verlag GmbH Germany, part of Springer Nature 2020

\begin{abstract}
The corrosion behavior of stainless steel exposed to a simulated salt lake atmosphere has been investigated by analyzing the evolution of surface morphologies and corrosion products, the initiation and development of pits, and the electrochemical characteristics. The results indicated that $\left(\mathrm{Mg}_{6} \mathrm{Fe}_{2}(\mathrm{OH})_{16}\left(\mathrm{CO}_{3}\right)\left(\mathrm{H}_{2} \mathrm{O}\right)_{4.5}\right)_{0.25}$, a layered double hydroxide, has been detected for the first time in the corrosion products formed on stainless steel exposed to a simulated salt lake atmosphere. The specimens exposed to $\mathrm{MgCl}_{2}$ deposit conditions were corroded more severely than those exposed to $\mathrm{NaCl}$ deposit conditions, which was attributed to the differences in the deliquescence relative humidity and efflorescence relative humidity values of $\mathrm{MgCl}_{2}$ and $\mathrm{NaCl}$. In addition, a special corrosion morphology consisting of a concentric circle of yellowish material was observed on the specimens exposed to $\mathrm{MgCl}_{2}$ deposit conditions, which was attributed to the formation of $\mathrm{Mg}(\mathrm{OH})_{2}$, inhibiting the diffusion and migration of $\mathrm{OH}^{-}$ions to the anode region. The maximum pit depth followed a power function with respect to corrosion time. The corrosion mechanism of stainless steel exposed to a simulated salt lake atmosphere is also discussed.
\end{abstract}

Keywords Atmospheric corrosion $\cdot$ Stainless steel $\cdot$ Salt lake atmosphere $\cdot$ Pitting corrosion

\section{Introduction}

Stainless steels, which exhibit strong passivity, are usually exposed to various atmospheric environments, but are susceptible to localized attacks like pitting in environments containing $\mathrm{Cl}^{-}$, such as a marine atmosphere. Many researchers have therefore investigated the atmospheric corrosion behaviors of stainless steels in the past decades, and these studies have been mainly focused on $\mathrm{Cl}^{-}$-rich marine atmospheres [1-5]. Liang et al. gave a summary of exposure testing of

Available online at http://link.springer.com/journal/40195.

Chen Pan

cpan@imr.ac.cn

$\triangle$ Zhenyao Wang

zhywang@imr.ac.cn

1 Institute of Metal Research, Chinese Academy of Sciences, Shenyang 110016, China

2 School of Materials Science and Engineering, University of Science and Technology of China, Shenyang 110016, China

3 University of Chinese Academy of Sciences, Beijing 100049, China stainless steels for atmospheric corrosion for 12 years and concluded that $\mathrm{Cl}^{-}$was the most corrosive element in a humid marine atmosphere [6]. Tsutsumi et al. investigated the pitting corrosion mechanism of type 304 stainless steel in marine atmospheres and concluded that pitting corrosion progressed only when the $\left[\mathrm{Cl}^{-}\right]$exceeded $6 \mathrm{M}$ (relative humidity ( $\mathrm{RH})$ is $<65 \%$ ) [7].

It is known that atmospheric corrosion occurs owing to the interactions of materials with climatic factors [8-10]. Because of our vast territory and complex climate conditions, the atmospheric corrosion behaviors and mechanisms of different metals in different regions must be varied [11]. Northwest China has hundreds of salt lakes, and its climate is characterized by arid-rainless conditions and land salinization, as a result of which the salt lake atmosphere is usually rich in $\mathrm{MgCl}_{2}$ and extremely dry with low relative humidity RH $(<50 \%$, even about $30 \% \mathrm{RH})$, as is shown in Table 1 . This is very different from a typical marine atmosphere with high relative humidity $(>80 \%)[12,13]$. This indicates that the corrosion behaviors of metals in a salt lake atmosphere may be different from those in a marine atmosphere, although chloride ions are also present in both atmospheric environments. Some studies have been carried out to investigate the atmospheric corrosion of metals in a salt lake atmosphere, and 
Table 1 Regional climatic factors of sites around the salt lake atmosphere

\begin{tabular}{lllllll}
\hline Region & $\begin{array}{l}\text { Wind veloc- } \\
\text { ity }\left(\mathrm{m} \mathrm{s}^{-1}\right)\end{array}$ & $\begin{array}{l}\text { Tempera- } \\
\text { ture }\left({ }^{\circ} \mathrm{C}\right)\end{array}$ & $\begin{array}{l}\text { Sunshine dura- } \\
\text { tion }\left(\mathrm{h} \mathrm{year}{ }^{-1}\right)\end{array}$ & $\begin{array}{l}\text { Precipitation } \\
\left(\mathrm{mm} \mathrm{year}^{-1}\right)\end{array}$ & $\begin{array}{l}\text { Evaporation } \\
\left(\mathrm{mm} \mathrm{year}^{-1}\right)\end{array}$ & RH (\%) \\
\hline Mangya & 4 & 1.4 & 3289.7 & 45.2 & 2930.8 & 31 \\
Lenghu & $3-4$ & 2.3 & 3550.5 & 16.5 & 3364.5 & 29 \\
Chaehan & 4 & 5.1 & 3158.9 & 24.9 & 3610.8 & 29 \\
Geerum & $3-4$ & 4.2 & 3073.3 & 38.6 & 2306.8 & 34 \\
Dachaidan & 2 & 1.1 & 3240.4 & 82.8 & 2031.8 & 35 \\
\hline
\end{tabular}

these demonstrated that the corrosion rates of non-passivated metals such as carbon steel exposed to a salt lake atmosphere were lower than those of non-passivated metals exposed to most marine atmospheres. In contrast, passivated metals such as aluminum alloys suffered more severe pitting corrosion than those exposed to marine environments [14]. In addition, layered double hydroxides (LDH) were also detected among the corrosion products formed on steels and aluminum alloys in a salt lake atmosphere [15-17]. However, the atmospheric corrosion mechanism of stainless steel is still obscure; it is thus necessary to investigate the corrosion behavior of stainless steel in a salt lake atmosphere.

The key to the concept of atmospheric corrosion is the existence of highly concentrated small-volume solutions, of which $\mathrm{Cl}^{-}$-rich solutions are particularly noteworthy. The concentration of $\mathrm{Cl}^{-}$-rich solutions is determined by the RH to which the solution is exposed. In an actual atmospheric environment, the RH generally increases at night and decreases during the daytime, so the concentration of $\mathrm{Cl}^{-}$is constantly changing [18-21]. Therefore, due to the relatively lower humidity of a salt lake atmosphere compared with a marine atmosphere, the $\mathrm{Cl}^{-}$concentration of a thin solution film may be different, and thus stainless steels exposed to a salt lake atmosphere may exhibit unique corrosion behavior.

In addition, as $\mathrm{MgCl}_{2}$ has a low deliquescence $\mathrm{RH}$ (DRH, 33\%) which could extend the wetness time, it is commonly used for atmospheric corrosion tests of stainless steel in the laboratory, and stainless steels are more prone to pitting corrosion from $\mathrm{MgCl}_{2}$ than $\mathrm{NaCl}$ (high DRH, 75\%) [22, 23]. Street et al. used $\mathrm{MgCl}_{2}$ droplets and observed the morphology of atmospheric pitting corrosion of 304L stainless steels. They found that the morphology is a sensitive function of RH and chloride deposition density (CDD) [18]. Frankel et al. studied the pitting corrosion of 304 stainless steel under drops of $\mathrm{MgCl}_{2}$ solution and determined the influence of $\mathrm{Cl}^{-}$concentration and the drop size on pit initiation time and initiation
$\mathrm{Cl}^{-}$concentration [24]. Hastuty et al. investigated pitting corrosion of stainless steels under drops of $\mathrm{MgCl}_{2}$ solutions in order to clarify the critical $\mathrm{RH}$ for the initiation of pitting corrosion [25]. Although some excellent results have been obtained, there has been only scarce research on the corrosion behavior and mechanism of stainless steels under periodic wet-dry cycle conditions to simulate the atmospheric environment of a salt lake.

In the present work, the corrosion behaviors of 304 stainless steels under periodic wet-dry cycle conditions, where temperature and $\mathrm{RH}$ are set according to an actual salt lake atmosphere, have been investigated. Also, the evolution of the morphologies, composition, initiation, and development of pits is discussed. The results of this study provide a detailed understanding of the corrosion behavior of stainless steel under a natural salt lake atmosphere.

\section{Experimental}

\subsection{Materials Preparation}

The chemical composition of 304 stainless steel, which was selected as the experimental specimen, is listed in Table 2. The plate specimens were cut into dimensions of $50 \mathrm{~mm} \times 25 \mathrm{~mm} \times 3 \mathrm{~mm}$ and $50 \mathrm{~mm} \times 20 \mathrm{~mm} \times 3 \mathrm{~mm}$ (to better distinguish samples tested under different corrosion media). Then, the specimens were ground with $\mathrm{SiC}$ grit paper, cleaned ultrasonically with acetone, rinsed with alcohol, and finally stored in a desiccator for $24 \mathrm{~h}$. The specimens for the electrochemical tests were cut to a size of $10 \mathrm{~mm} \times 10 \mathrm{~mm} \times 3 \mathrm{~mm}$ and were then embedded in an epoxy resin with an exposed working area of $1 \mathrm{~cm}^{2}$. Electrode specimens were also ground, cleaned, and dried according to the aforementioned procedure and were then employed for electrochemical measurements.
Table 2 Chemical compositions of the 304 stainless steel (wt\%)

\begin{tabular}{llllllll}
\hline $\mathrm{C}$ & $\mathrm{Si}$ & $\mathrm{Mn}$ & $\mathrm{S}$ & $\mathrm{P}$ & $\mathrm{Cr}$ & $\mathrm{Ni}$ & $\mathrm{Fe}$ \\
0.06 & 0.68 & 1.22 & 0.030 & 0.019 & 18.59 & 8.52 & $\mathrm{Bal}$. \\
\hline
\end{tabular}




\subsection{Wet-Dry Accelerated Test}

Among many indoor tests, the wet-dry cyclic accelerated test can better reproduce the key characteristics of atmospheric environment, wherein the relative humidity and temperature are the most important factors alternate by day and by night $[5,26]$. Thus, the wet-dry cyclic accelerated test was conducted using a climatic test chamber (C4180 pro) and the experimental parameters were set according to climate conditions in the salt lake area. In order to explore the influence of $\mathrm{MgCl}_{2}$, a comparative group experiment was performed using a $\mathrm{NaCl}$ corrosive medium. The corrosion tests involved the following steps within a period of $48 \mathrm{~h}$ : (1) coating of the sample surface with $20 \mu \mathrm{L} / \mathrm{cm}^{2}$ of $0.2 \mathrm{~mol} / \mathrm{L}$ $\mathrm{MgCl}_{2}$ (simulating a salt lake atmosphere) or $0.4 \mathrm{~mol} / \mathrm{L}$ $\mathrm{NaCl}$ (comparative group experiment), (2) drying of the sample in an oven at $40^{\circ} \mathrm{C}$, (3) wetting of the sample in the test box set at $30{ }^{\circ} \mathrm{C}$ and $\mathrm{RH}$ of $80 \%$ for $60 \mathrm{~min}$, (4) drying the sample again in the box maintained at $30{ }^{\circ} \mathrm{C}$ and $\mathrm{RH}$ of $20 \%$ for $120 \mathrm{~min}$, and (5) repeating steps (3) to (4) fifteen times. The test specimens were retrieved for analysis after 10, 20, 30, 40, 50, and 60 days. The retrieved specimens were immersed in a specific chemical solution $(100 \mathrm{~mL}$ nitric acid $+900 \mathrm{~mL}$ distilled water) and vigorously stirred at $60{ }^{\circ} \mathrm{C}$ for about $20 \mathrm{~min}$ to remove the corrosion products according to the International Organization for Standardization (ISO) 8407 standard. Then, the specimens were rinsed with distilled water, dried in warm air, and then kept in the desiccator for analysis.

\subsection{Analysis of Corrosion Products}

The surface morphologies of the corrosion products were observed using scanning electron microscopy (SEM, XL30 FEG). The elemental distribution was mapped using an electron probe micro-analyzer (EPMA, Shimadzu Model EPMA-1610) at an accelerating voltage of $15 \mathrm{kV}$. The 3D morphologies and depth of pit statistics were observed using a white-light interferometer (MicroXAM) after removing the corrosion products.

The chemical composition of the corrosion products was determined by complementary methods. X-ray diffraction (XRD, Philips X'Pert MPD) measurements were conducted using a Rigaku D/Max-2000 diffractometer with a $\mathrm{Cu} K_{\alpha}$ target operated at $50 \mathrm{kV}$ and $250 \mathrm{~mA}$, with a $2 \theta$ range of $10^{\circ}-80^{\circ}$ and scanning speed of $1^{\circ} \mathrm{min}^{-1}$. X-ray photoelectron spectroscopy (XPS, ESCALAB 250) depth profile measurements were performed on stainless steel specimens after 10, 20, 30, 40, 50, and 60 days of corrosion time. The core-level spectra of the main elements in the alloy and the $\mathrm{O} 2 p$ and $\mathrm{C} 1 s$ spectra were recorded with monochromatic $\mathrm{Al} K \alpha(1486.6 \mathrm{eV})$ radiation. The measured specimen current during the depth profiling experiment was $2 \mu \mathrm{A}$, and the bombardment area had dimensions of $2 \mathrm{~mm} \times 2 \mathrm{~mm}$.

\subsection{Electrochemical Measurements}

Electrochemical tests were performed using a PARSTAT 2273. A conventional three-electrode system was adopted for all electrochemical measurements: corroded working electrode, platinum plate counter electrode, and saturated calomel reference electrode (SCE). In the case of electrochemical impedance spectroscopy (EIS) measurements, the amplitude of the AC voltage was $10 \mathrm{mV}$ and the frequency was in the range of $10^{5}$ to $10^{-2} \mathrm{~Hz}$. The test solution was a $0.2 \mathrm{M} \mathrm{MgCl}_{2}$ solution prepared from reagent-grade chemicals and distilled water. Prior to EIS measurements, the samples were left freely immersed in the solution for $3600 \mathrm{~s}$ to reach a steady state, and all the measurements were carried out at room temperature. The frequency scanning during EIS was always performed in a direction from high to low frequency, and the EIS data were analyzed with ZSimpWin software.

\subsection{Constant Humidity Test}

A constant humidity test was designed (at $80 \% \mathrm{RH}$ ), and it involved the following steps. The surface of the samples was coated with $20 \mu \mathrm{L} / \mathrm{cm}^{2}$ of $0.2 \mathrm{~mol} / \mathrm{L} \mathrm{MgCl}_{2}$ (simulating a salt lake atmosphere) or $0.4 \mathrm{~mol} / \mathrm{L} \mathrm{NaCl}$ (comparative group experiment). Then, the samples were dried in an oven at $40{ }^{\circ} \mathrm{C}$, wetted in the test box set at $\mathrm{RH}$ of $80 \%$, and finally retrieved for analysis after 2 days.

\section{Results}

\subsection{Morphology of Specimens Under Periodic Wet- Dry Cycle Conditions}

Figure $1 \mathrm{a}-\mathrm{f}, \mathrm{a}_{1}-\mathrm{f}_{1}$ depicts the macro-morphologies of the corrosion products formed on 304 stainless steel samples exposed to a simulated salt lake atmosphere after 10, 20, $30,40,50$, and 60 days of corrosion under $\mathrm{MgCl}_{2}$ deposit condition and under $\mathrm{NaCl}$ deposit condition, respectively. As the corrosion time was extended, yellow corrosion products formed on stainless steel under $\mathrm{MgCl}_{2}$ deposit condition gradually accumulated. However, very few dispersive corrosion products were formed at the edge of the stainless steels under $\mathrm{NaCl}$ deposit condition. The results of macromorphologies indicate that the corrosion of stainless steels under $\mathrm{MgCl}_{2}$ deposit condition is more serious than that under $\mathrm{NaCl}$ deposit condition.

Figure $2 \mathrm{a}-\mathrm{f}, \mathrm{a}_{1}-\mathrm{f}_{1}$ displays the macro-morphologies after removing the corrosion products formed on stainless steel 


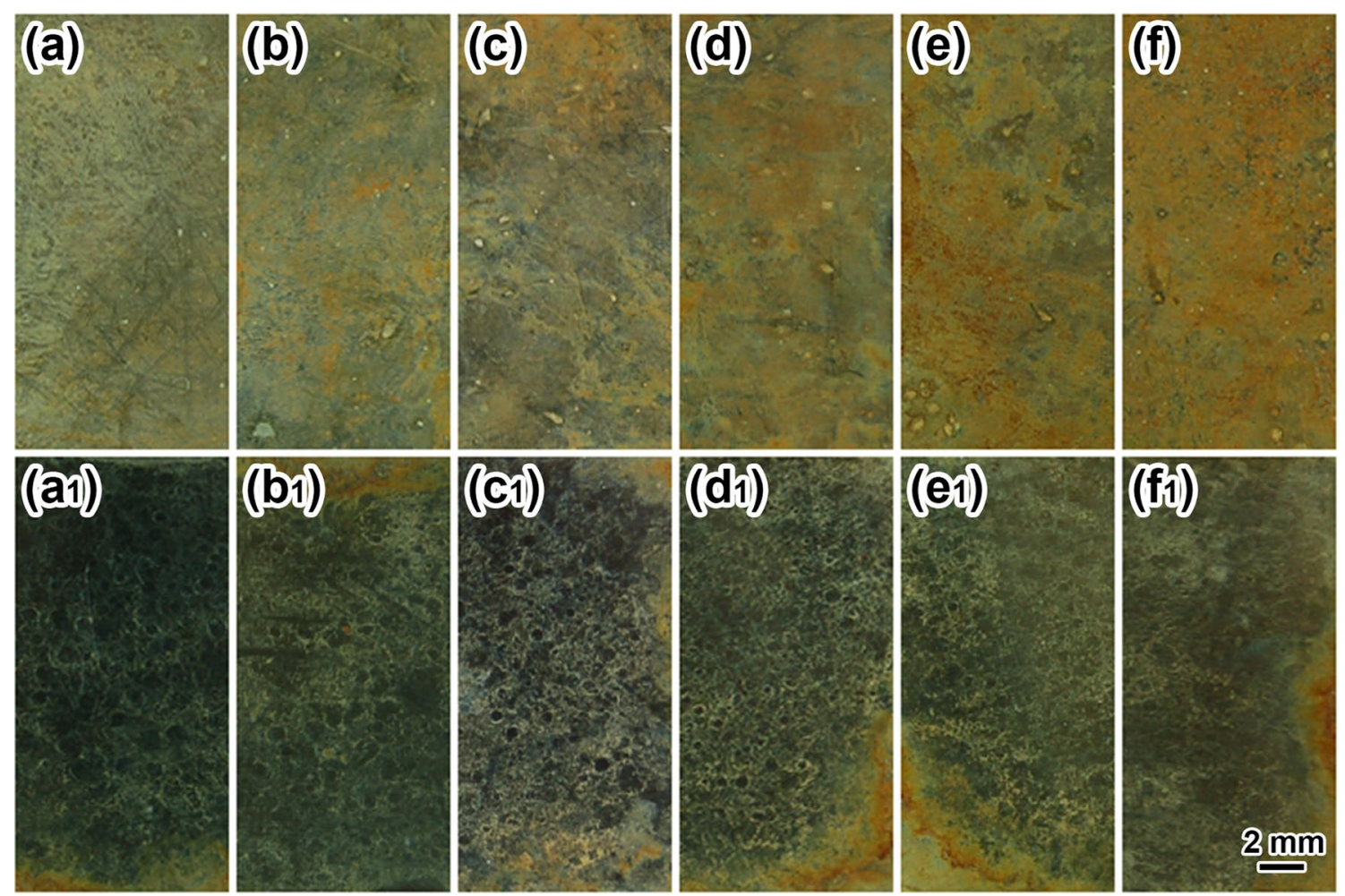

Fig. 1 Macro-morphologies of 304 stainless steel as a function of corrosion time: $\mathbf{a}-\mathbf{f}$ under $\mathrm{MgCl}_{2}$ deposit condition, $10-60$ days; $\mathbf{a}_{\mathbf{1}}-\mathbf{f}_{\mathbf{1}}$ under $\mathrm{NaCl}$ deposit condition, 10-60 days

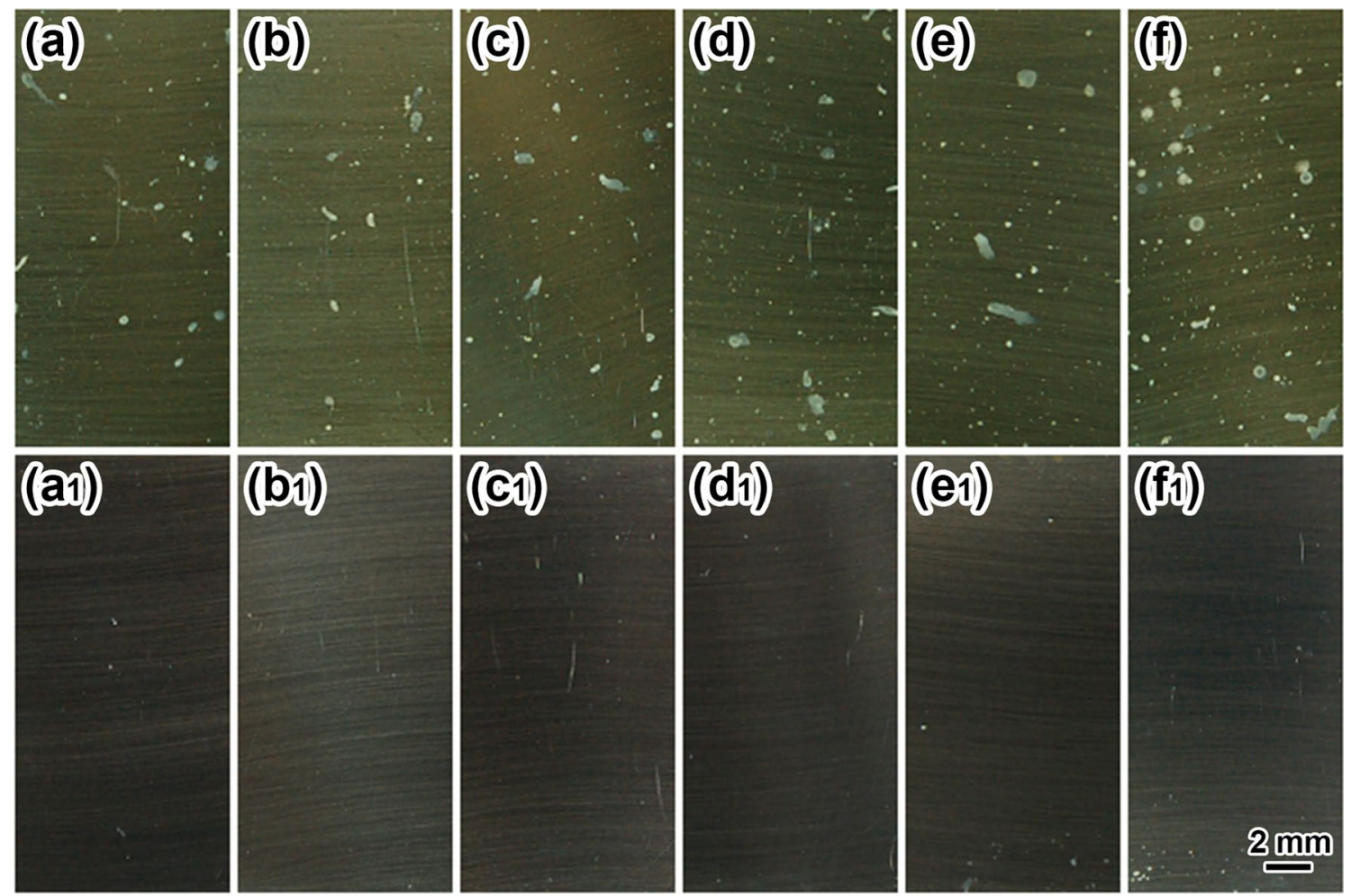

Fig. 2 Macro-morphologies of 304 stainless steel after removing corrosion products as a function of corrosion time: a-f under $\mathrm{MgCl}_{2}$ deposit condition, 10-60 days; $\mathbf{a}_{\mathbf{1}}-\mathbf{f}_{\mathbf{1}}$ under $\mathrm{NaCl}$ deposit condition, 10-60 days 
under $\mathrm{MgCl}_{2}$ deposit condition and under $\mathrm{NaCl}$ deposit condition, respectively. Many naked white pits could be evidently observed on the sample surface under $\mathrm{MgCl}_{2}$ deposit condition. However, almost no pits were observed on the sample surface under the $\mathrm{NaCl}$ deposit condition.

Figure 3 depicts a series of SEM images showing the evolution of the micro-morphologies of corrosion products formed on stainless steels under $\mathrm{MgCl}_{2}$ deposition condition after 10-60 days of corrosion. As the corrosion time progressed, more and more corrosion products were deposited on the sample surfaces, almost covering the entire surface.
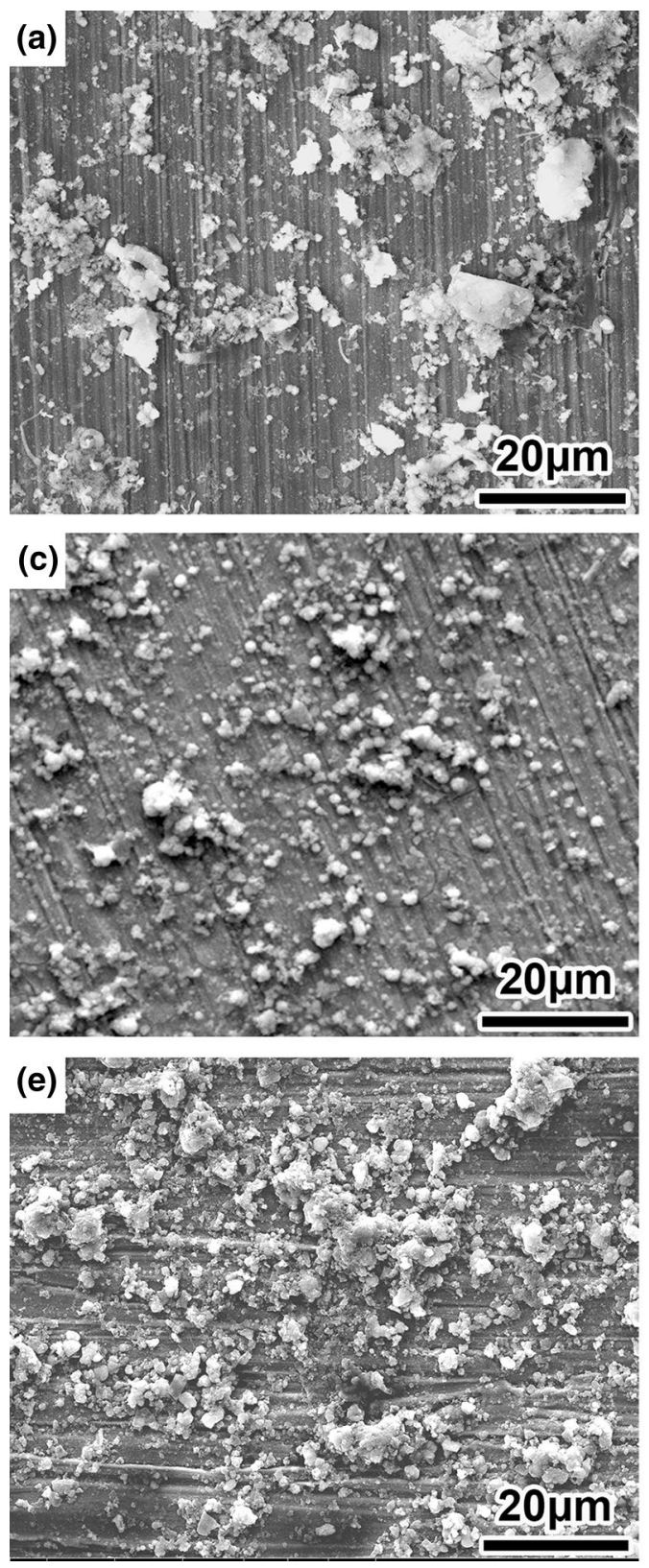

\subsection{Composition of Corrosion Products}

It is known that the composition of corrosion products can directly influence the subsequent corrosion behavior of metals $[27,28]$. In order to understand the evolution of the composition and further illustrate the effect of corrosion products on the corrosion behavior of stainless steel, XRD was used to gain information about the composition of the corrosion products. Figure 4 shows the XRD patterns of the corrosion products formed on 304 stainless steels under $\mathrm{MgCl}_{2}$ deposit condition after 60 days of corrosion. In combination with the prior results [29-31], it can be deduced from these XRD
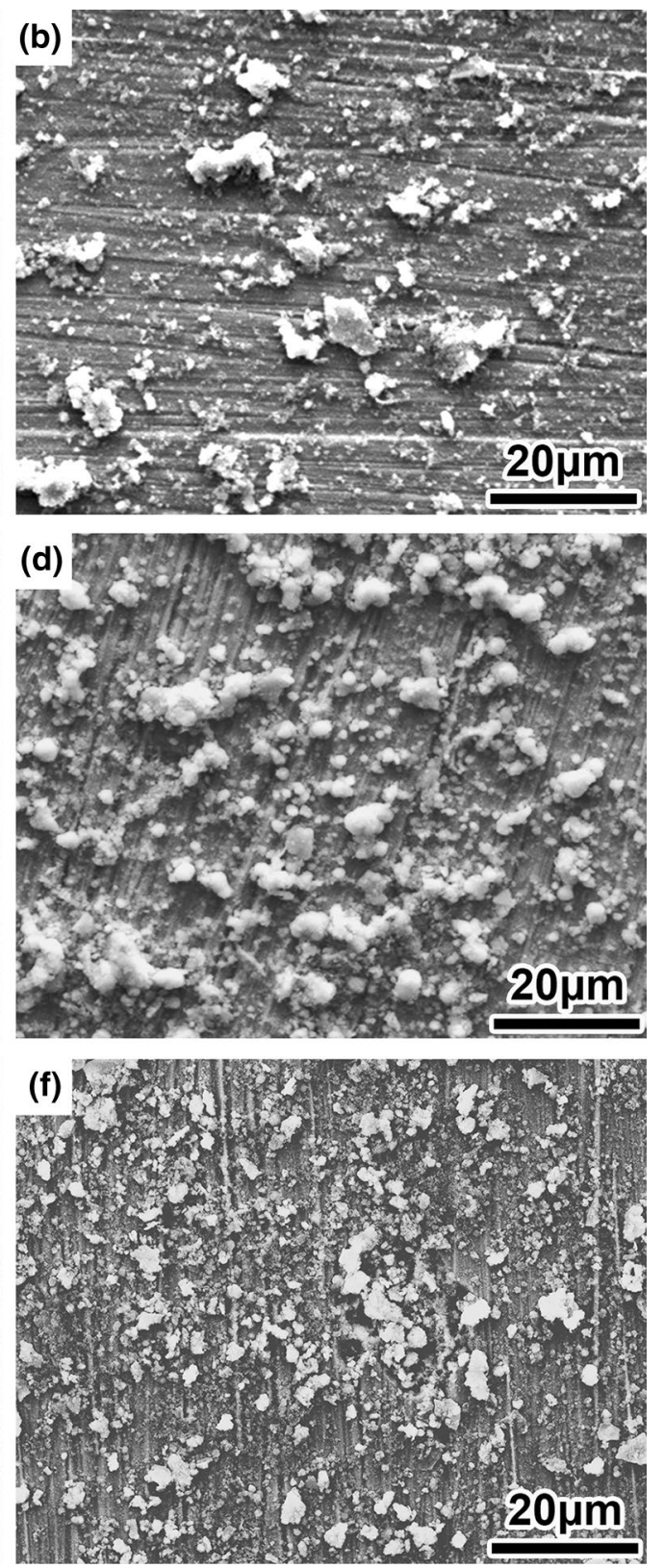

Fig. 3 Micro-morphologies of 304 stainless steel under $\mathrm{MgCl}_{2}$ deposit condition for a 10 days, b 20 days, c 30 days, d 40 days, e 50 days, $\mathbf{f}$ 60 days 


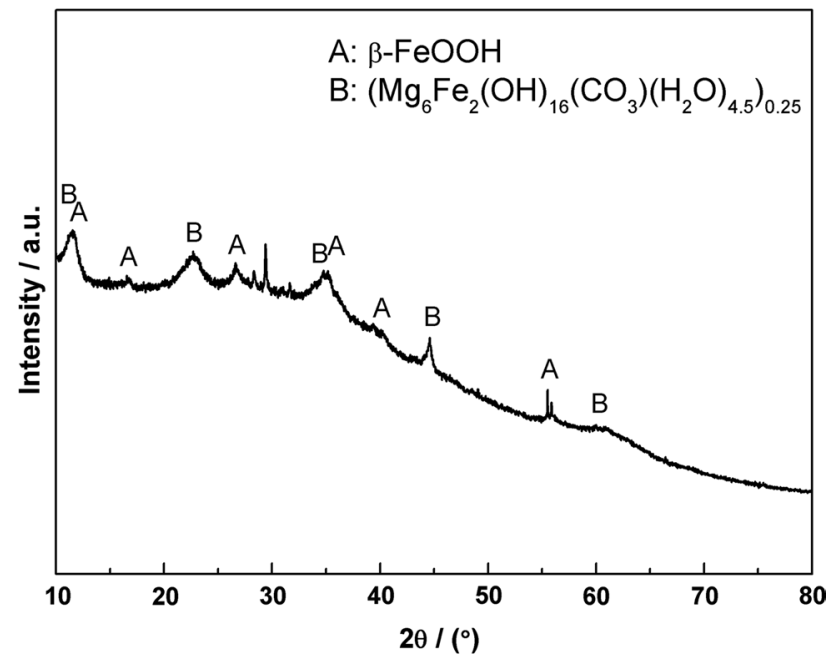

Fig. 4 XRD spectra of the corrosion products formed on 304 stainless steel under $\mathrm{MgCl}_{2}$ deposit condition

patterns that the corrosion products were mainly composed of $\beta-\mathrm{FeOOH}$ and $\left(\mathrm{Mg}_{6} \mathrm{Fe}_{2}(\mathrm{OH})_{16}\left(\mathrm{CO}_{3}\right)\left(\mathrm{H}_{2} \mathrm{O}\right)_{4.5}\right)_{0.25}$-a general formula of $\mathrm{CO}_{3}$-LDH. It is known that $\mathrm{pH}$ value (8-10) and supersaturation of the solution are two key factors in the synthesis of LDH [32-34]. Firstly, as most of $\mathrm{MgCl}_{2}$ deposited in our experiment, the solution formed on sample surface was usually saturated. And secondly, the corrosion of stainless steel in the simulated salt lake atmosphere led to the formation of $\mathrm{Fe}(\mathrm{OH})_{3}$. Meanwhile, with the increase in $\mathrm{pH}$ value, $\mathrm{Mg}(\mathrm{OH})_{2}$ precipitated in the local regions which provide sites for oxygen reduction. Both key factors could be met in the corrosion process. That is to say, after a series of complex reaction steps between $\mathrm{Fe}(\mathrm{OH})_{3}$ and $\mathrm{Mg}(\mathrm{OH})_{2}$, LDH is likely to form $[16,30]$.

Due to the small amount of corrosion products formed on 304 stainless steel, it was impossible to obtain information on the composition evolution of the corrosion products as a function of corrosion time by using XRD analysis. Thus, in the present study, XPS was adopted to provide more information about the composition of the corrosion products in order to reveal the composition evolution of corrosion products. Figure 5 displays the XPS spectra of the 304 stainless steels under $\mathrm{MgCl}_{2}$ deposit condition after 60 days of corrosion. In particular, the figure shows the $\mathrm{Fe} 2 p_{2 / 3}, \mathrm{Mg} 1 s, \mathrm{C}$ $1 s, \mathrm{O} 1 s, \mathrm{Cr} 2 p_{2 / 3}$, and $\mathrm{Ni} 2 p_{2 / 3}$ core-level spectra. The XPS results showed that the kinds of corrosion products did not change with the increase in the sputtering time to $135 \mathrm{~s}$. The $\mathrm{Fe} 2 p_{2 / 3}$ peak positions were observed at 707.5, 709.4, 710.7, and $711.7 \mathrm{eV}$, corresponding to $\mathrm{Fe}$ (metal), $\mathrm{Fe}(\mathrm{II})$ oxide, $\mathrm{Fe}$ (III) oxide, and Fe(III) hydroxide, respectively (Fig. 5a). However, the peak at $714.3 \mathrm{eV}$ has not been referenced so far in the literature. In our opinion, it should be assigned to LDH (confirmed by the XRD results). The Mg $1 s$ peak has been systematically decomposed into three components: LDH located at a binding energy (BE) of $1305.1 \mathrm{eV}$, $\mathrm{Mg}$ (II) oxide at $\mathrm{BE}$ of $1303.9 \mathrm{eV}$, and $\mathrm{Mg}$ hydroxide at $\mathrm{BE}$ of $1302.7 \mathrm{eV}$ (Fig. 5b). In the $\mathrm{C} 1 s$ region, the peaks at 284.8 and $289 \mathrm{eV}$ were assigned to $\mathrm{C}$ and $\mathrm{CO}_{3}{ }^{2-}$, respectively (Fig. 5c). This indicates that carbon is involved in the corrosion process, which is consistent with the results obtained by XRD. The $\mathrm{O} 1 s$ peaks were mainly attributed to $\mathrm{O}^{2-}(530.3 \mathrm{eV}), \mathrm{OH}^{-}(531.2 \mathrm{eV})$, and $\mathrm{H}_{2} \mathrm{O}(532.5 \mathrm{eV})$, which played the role of connecting metal ions (Fig. $5 \mathrm{~d}$ ). The $\mathrm{Cr} 2 p_{2 / 3}$ peak positions were at 574.6, 576.4, 577.4, and $578.8 \mathrm{eV}$, corresponding to $\mathrm{Cr}$ (metal), $\mathrm{Cr}$ (III) oxide, $\mathrm{Cr}$ (III) hydroxide, and $\mathrm{Cr}(\mathrm{VI})$ oxide, respectively (Fig. 5e). The $\mathrm{Ni}$ peak positions at 855.6 and $856.5 \mathrm{eV}$ were also observed and assigned to $\mathrm{Ni}$ (II) oxide and $\mathrm{Ni}$ hydroxide, respectively (Fig. 5f).

\subsection{EIS Results}

The protective ability of the corrosion products formed on specimens was evaluated. For this purpose, EIS was used to investigate the electrochemical processes occurring between the specimen and its surrounding environment $[35,36]$. Figure $6 a, b$ represents the Nyquist and Bode diagrams of the unexposed and the rusted stainless steels in a $0.2 \mathrm{~mol} \mathrm{~L}^{-1} \mathrm{MgCl}_{2}$ solution as a function of the exposure time, respectively. Meanwhile, a general simplified equivalent circuit (Fig. 6c) model is applied to fit the impedance data. Elements used in the equivalent circuit are as follows: $R_{\mathrm{S}}$ denotes the electrolyte resistance, while $R_{\mathrm{r}}$ and $R_{\mathrm{ct}}$ represent the corrosion product film resistance and the charge transfer resistance, respectively. $Q_{\mathrm{r}}$ and $Q_{\mathrm{dl}}$ represent the rust capacitance and double-layer capacitance, respectively. The EIS fitting parameters for specimens in $0.2 \mathrm{~mol} \mathrm{~L}^{-1} \mathrm{MgCl}_{2}$ solution are listed in Table 3.

Notably, the value of $R_{\mathrm{ct}}$ of unexposed specimens is much higher than that of corroded specimens for different corrosion periods, which implies that a native passive film formed on stainless steel could provide protection to the substrate against corrosive ions, resulting in the inhibition of the charge transfer process and a higher value of $R_{\mathrm{ct}}$. After 10 days of corrosion, the native passive film on the specimen was partially destroyed and the few corrosion products formed on the stainless steel could not protect the substrate, leading to a significant decrease in $R_{\mathrm{ct}}$. However, it can be clearly seen that $R_{\mathrm{ct}}$ shows an increasing trend after 20 days of corrosion. $R_{\mathrm{ct}}$ reflects the inhibition of the charge transfer process. As corrosion time progressed, more and more corrosion products were formed on the stainless steel surface, which could effectively resist the invasion 
(a)

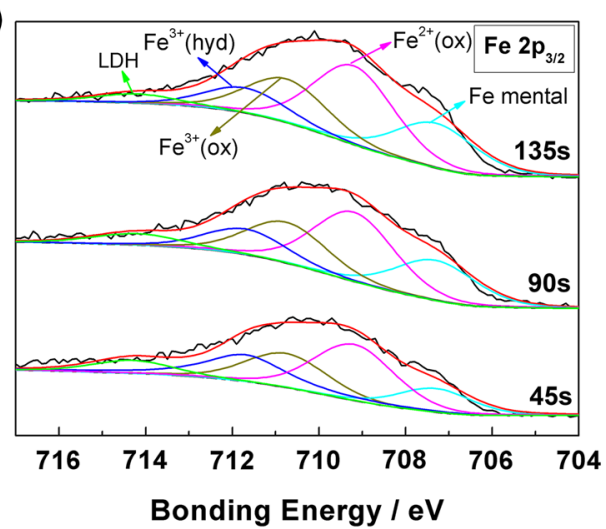

(c)

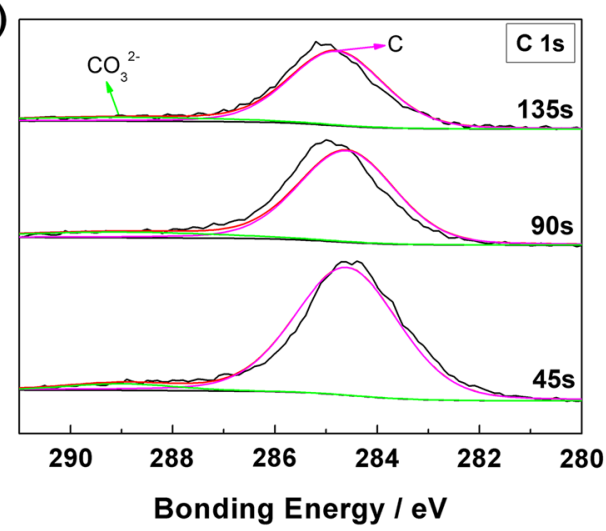

(e)

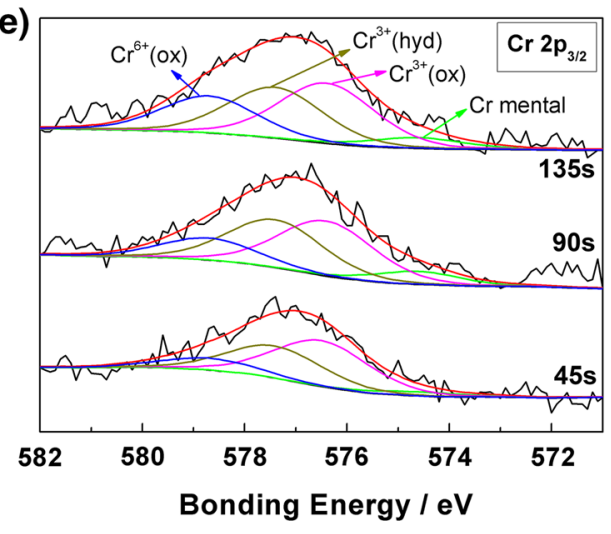

(b)

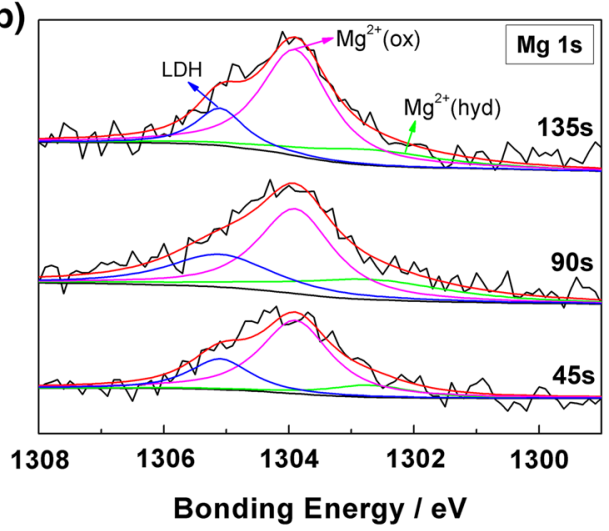

(d)

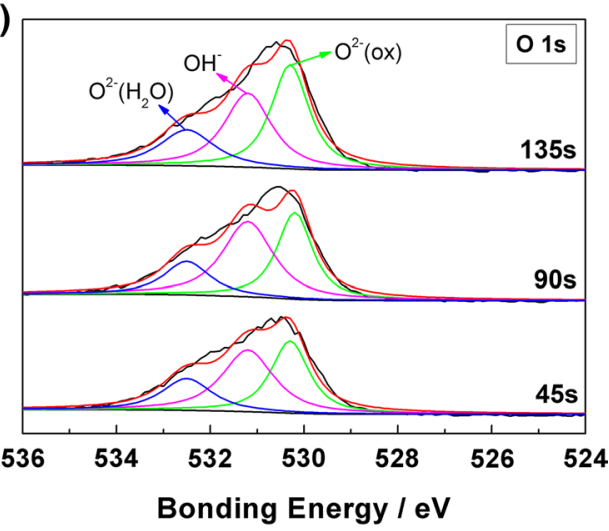

(f)

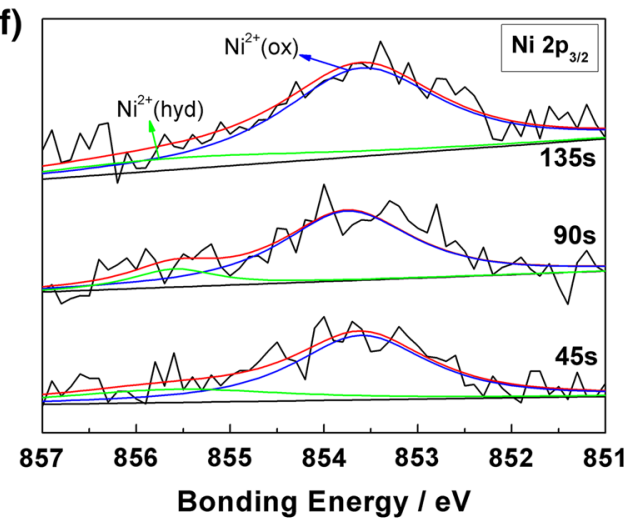

Fig. 5 XPS spectra increase in the sputtering time to $135 \mathrm{~s}$ observed for 304 stainless steel under $\mathrm{MgCl}_{2}$ deposit condition for 60 days of corrosion in $\mathrm{Fe} 2 p_{3 / 2}$ a, $\mathrm{Mg} 1 s \mathbf{b}, \mathrm{C} 1 s \mathbf{c}, \mathrm{O} 1 s \mathbf{d}, \mathrm{Cr} 2 p_{3 / 2} \mathbf{e}, \mathrm{Ni} 2 p_{3 / 2} \mathbf{f}$

of corrosion media and then block the charge transfer process, resulting in an increase in $R_{\mathrm{ct}}$. Although some studies have calculated corrosion rate from polarization resistance $\left(R_{\mathrm{p}}\right)$ values [37], the charge transfer resistance $R_{\mathrm{ct}}$ is more intimately correlated with the corrosion rate than $R_{\mathrm{p}}$ because $R_{\mathrm{ct}}$ is determined only from Faradaic processes of the charge transfer-controlled corrosion [5, 38]; moreover, in instances when the impedance response displays more than one time constant, erroneous corrosion rates will be resulted when calculating the $R_{\mathrm{p}}$ [39].
Therefore, in the present work, the reciprocal of the charge transfer resistance $R_{\mathrm{ct}}$ was also considered as a parameter to characterize the corrosion rate of stainless steel exposed to a simulated salt lake atmosphere (Fig. 6d). Obviously, the initial value of $1 / R_{\mathrm{ct}}$ increased significantly before 30 days and then tended to decrease, which indicates that there was a transition from corrosion acceleration to deceleration. 

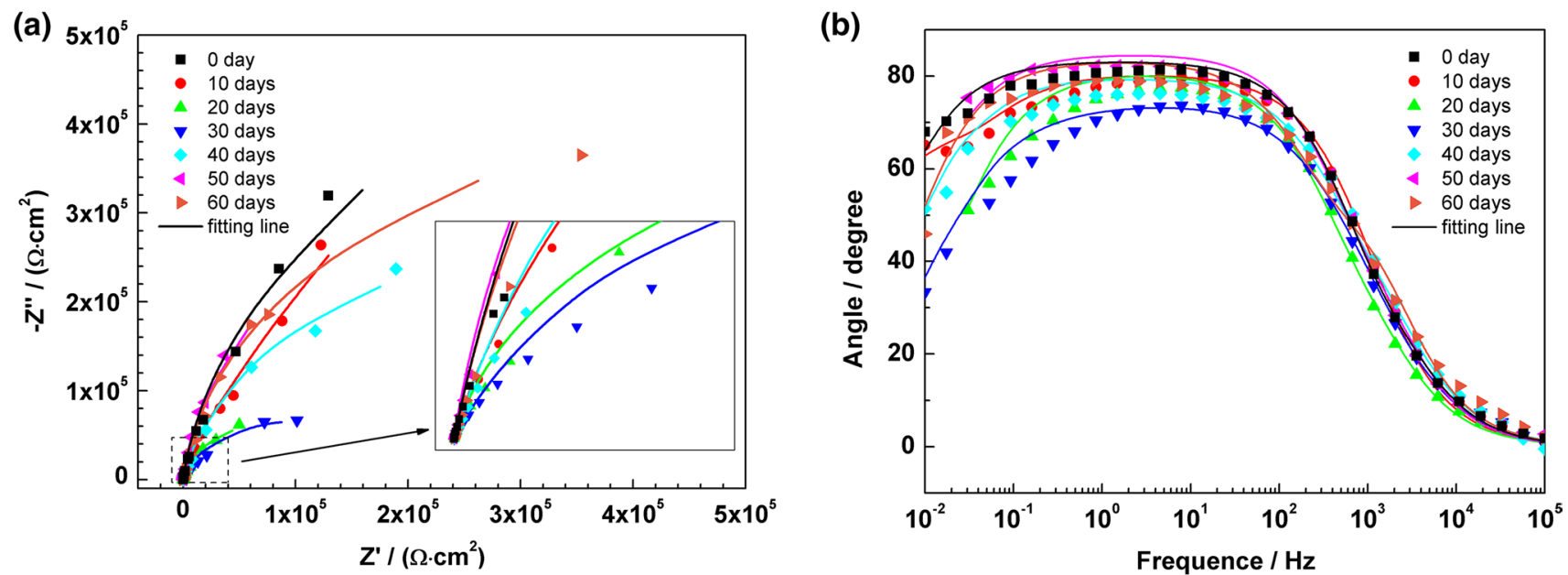

(c)

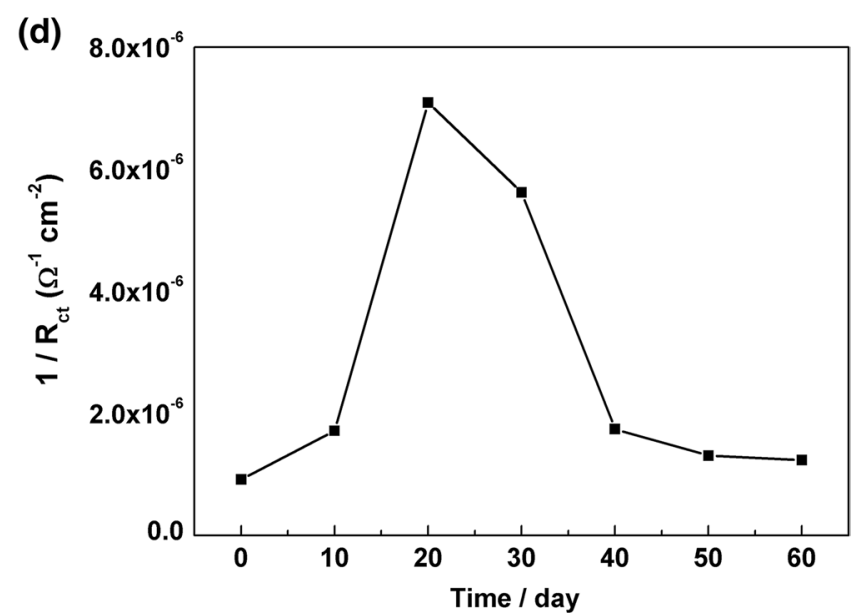

Fig. 6 Electrochemical test results of 304 stainless steel under $\mathrm{MgCl}_{2}$ deposit condition as a function of corrosion time: a Nyquist diagrams, b Bode diagrams, c equivalent circuit, $\mathbf{d}$ reciprocal of $R_{\mathrm{ct}}$

Table 3 Fitting results of EIS parameters

\begin{tabular}{|c|c|c|c|c|c|c|c|}
\hline \multirow[t]{2}{*}{ Parameters } & \multirow[t]{2}{*}{$R_{\mathrm{s}}\left(\Omega \mathrm{cm}^{2}\right)$} & \multicolumn{2}{|l|}{$Q_{\mathrm{r}}$} & \multirow[t]{2}{*}{$R_{\mathrm{r}}\left(\Omega \mathrm{cm}^{2}\right)$} & \multicolumn{2}{|l|}{$\underline{Q_{\mathrm{dl}}}$} & \multirow[t]{2}{*}{$R_{\mathrm{ct}}\left(\Omega \mathrm{cm}^{2}\right)$} \\
\hline & & $y_{\mathrm{r}}\left(\Omega^{-1} \mathrm{~cm}^{-2} \mathrm{~S}^{-n}\right)$ & $n_{\mathrm{r}}$ & & $\mathrm{y}_{\mathrm{dl}}\left(\Omega^{-1} \mathrm{~cm}^{-2} \mathrm{~S}^{-n}\right)$ & $n_{\mathrm{dl}}$ & \\
\hline $10(d)$ & 11.72 & $3.022 \times 10^{-5}$ & 0.8959 & $3.793 \times 10^{5}$ & $2.866 \times 10^{-5}$ & 1 & $7.192 \times 10^{5}$ \\
\hline $20(d)$ & 10.51 & $3.456 \times 10^{-5}$ & 0.9049 & 34.93 & $1.549 \times 10^{-5}$ & 0.892 & $1.41 \times 10^{5}$ \\
\hline $30(d)$ & 13.02 & $3.087 \times 10^{-5}$ & 0.8678 & 44.82 & $2.307 \times 10^{-5}$ & 0.7398 & $1.779 \times 10^{5}$ \\
\hline $40(d)$ & 11.9 & $1.95 \times 10^{-5}$ & 0.9049 & 45.84 & $1.337 \times 10^{-5}$ & 0.8592 & $5.745 \times 10^{5}$ \\
\hline $50(d)$ & 11.03 & $1.326 \times 10^{-5}$ & 0.9651 & 32.19 & $1.1654 \times 10^{-5}$ & 0.9171 & $7.645 \times 10^{5}$ \\
\hline $60(d)$ & 13.05 & $1.363 \times 10^{-5}$ & 0.9286 & 77.74 & $1.063 \times 10^{-5}$ & 0.927 & $8.109 \times 10^{5}$ \\
\hline
\end{tabular}




\section{Discussion}

\subsection{Effect of Periodic Wet-Dry Cycle on the Corrosion Behavior of 304 Stainless Steel Exposed to a Simulated Salt Lake Atmosphere}

Deliquescence is a process in which solid salts absorb water vapor to form a liquid electrolyte, which occurs at or above a specific RH value, the DRH. For the reverse process, the $\mathrm{RH}$ of deliquesced solution crystallization is called the efflorescence relative humidity (ERH). At a constant RH, a thin layer of chloride solution placed on a stainless steel surface will gradually evaporate to reach a chloride concentration in equilibrium $\left(\left[\mathrm{Cl}^{-}\right]_{\mathrm{eq}}\right)$ with the $\mathrm{RH}[7,26,40]$. The empirical relationship between the $\left[\mathrm{MgCl}_{2}\right]_{\mathrm{eq}}$ and $\mathrm{RH}$ (above the DRH of $33 \%$ ), as well as that between $[\mathrm{NaCl}]_{\mathrm{eq}}$ and $\mathrm{RH}$ (above the DRH of 75\%), is depicted in Fig. 7 [25, 41].

It is considered that the $\mathrm{Cl}^{-}$concentration required for pit initiation under the thinner electrolyte layer is about $6 \mathrm{M}$ [7]. Therefore, during the wet process when the $\mathrm{RH}$ in the

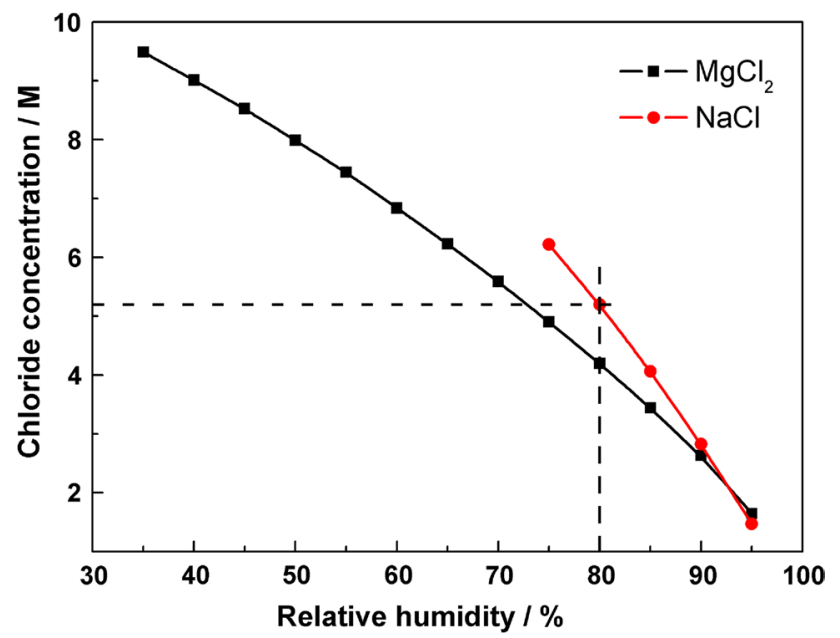

Fig. 7 Equilibrium concentration of chloride solution of $\mathrm{MgCl}_{2}$ and $\mathrm{NaCl}$ balanced with different $\mathrm{RH}$ of gas phase $[25,36]$ chamber increased from 20 to $80 \%$, the $\mathrm{Cl}^{-}$concentrations under $\mathrm{MgCl}_{2}$ and $\mathrm{NaCl}$ deposit conditions would gradually decrease and finally reach $4.2 \mathrm{M}$ and $5.2 \mathrm{M}$, respectively, according to the empirical relationship shown in Fig. 7, and at the same time, pits would start forming on the stainless steel surfaces. From the macro-morphologies of specimens shown in Figs. 1 and 2, it can be seen that more visible pits formed on stainless steel surface under $\mathrm{MgCl}_{2}$ deposit condition, while almost no visible pits were formed under $\mathrm{NaCl}$ deposit condition. It has been reported that the $\mathrm{RH}$ required for pit repassivation is 70-75\% (with a surface finish of 2000 grit) and 56-70\% (surface-polished with a $0.25 \mu \mathrm{m}$ diamond suspension) for 304 stainless steels under $\mathrm{MgCl}_{2}$ droplets $[21,42]$. In order to determine whether the pits can repassivate at RH $80 \%$ in the present tests and to illustrate the RH necessary for pit repassivation under different deposit conditions, a constant RH test was designed in which the RH was maintained at $80 \%$ for 2 days.

Figure 8 depicts the macro-morphologies of the specimens under $\mathrm{MgCl}_{2}$ and $\mathrm{NaCl}$ deposit conditions after 2 days of corrosion at $80 \% \mathrm{RH}$. It is obvious that the specimen exposed to $\mathrm{MgCl}_{2}$ deposit condition was corroded more severely than that exposed to $\mathrm{NaCl}$ deposit condition. Furthermore, it is worth noting that a special corrosion morphology was formed under $\mathrm{MgCl}_{2}$ deposit condition, as shown in Fig. 8b. There was a yellowish concentric circle around the corroded area, where the corrosion products were deposited. This typical type of pit was also observed by Tsutsumi et al. [7]. However, still no visible pits were formed on the specimen exposed to $\mathrm{NaCl}$ deposit condition. This indicates that during the wet process $(80 \% \mathrm{RH})$, the pitting corrosion was not completely repassivated under $\mathrm{MgCl}_{2}$ deposit condition, while very few pits could be initiated and the small pits were completely repassivated under $\mathrm{NaCl}$ deposit condition. Therefore, it can be concluded that the $\mathrm{RH}$ for pit repassivation might be related to the surface states of the specimens. In the present work, the $\mathrm{RH}$ values for pit repassivation under $\mathrm{MgCl}_{2}$ deposit condition were higher than $80 \% \mathrm{RH}$, while those under $\mathrm{NaCl}$ deposit condition were lower than $80 \%$ RH. The pitting corrosion
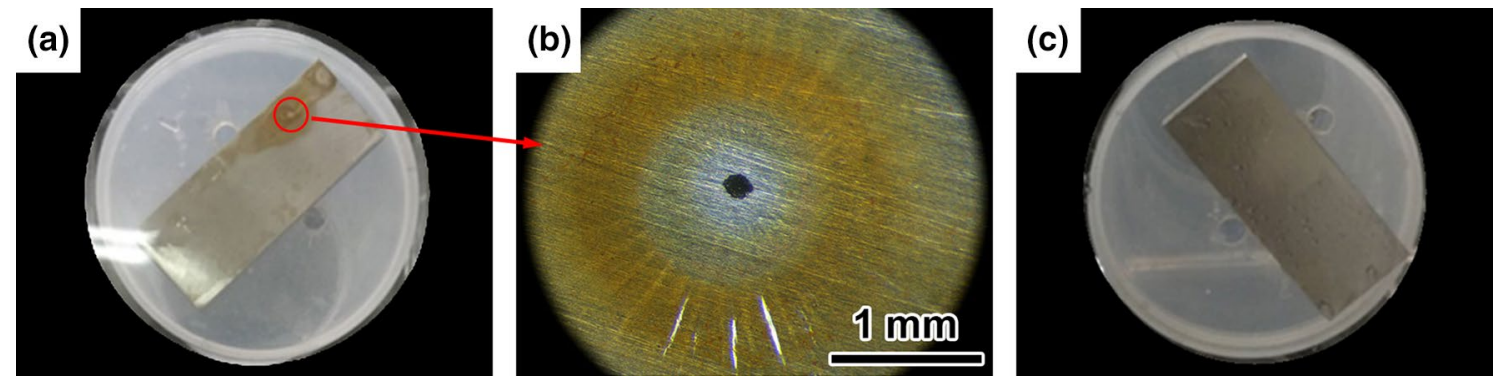

Fig. 8 Morphologies of 304 stainless steel after 2 days of corrosion: a $\mathrm{MgCl}_{2}$ deposit condition, b typical pits under $\mathrm{MgCl}_{2}$ deposit condition, $\mathbf{c}$ $\mathrm{NaCl}$ deposit condition 

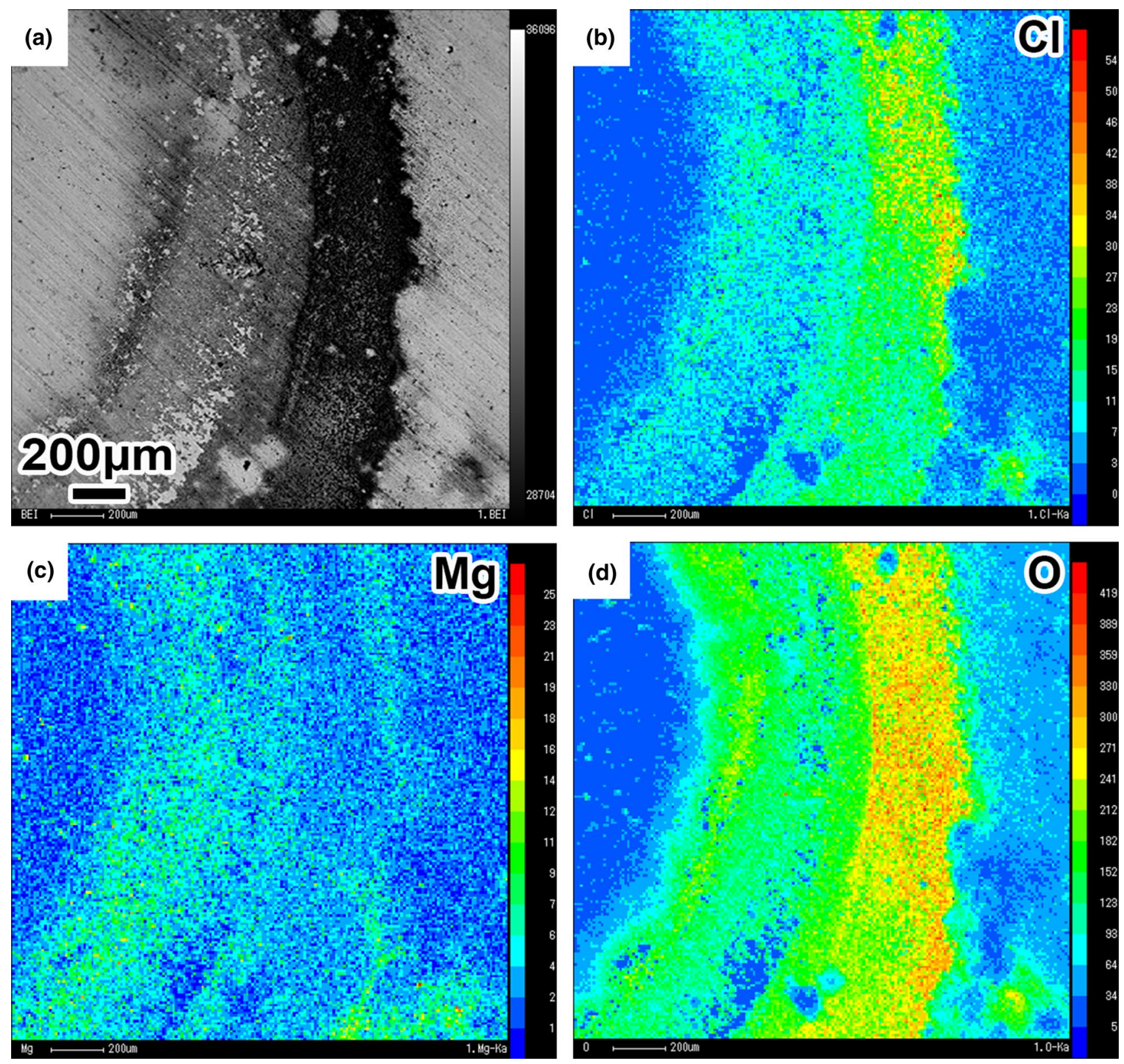

Fig. 9 Corrosion morphology a and distributions of $\mathrm{Cl} \mathbf{b}, \mathrm{Mg} \mathbf{c}, \mathrm{O} \mathbf{d}$ in corrosion products formed on 304 stainless steel under $\mathrm{MgCl}_{2}$ deposit condition after 2 days of corrosion

mechanism of 304 stainless steel exposed to a simulated lake atmosphere and the role played by $\mathrm{MgCl}_{2}$ in forming these typical pits will be explained in a later section.

During the dry process when the RH in the chamber decreased from 80 to $20 \%$, corrosion on the stainless steel surface under $\mathrm{NaCl}$ deposit condition was inhibited because there was insufficient water available to dissolve metal ions, as the $\mathrm{ERH}$ of $\mathrm{NaCl}$ has been reported to be 41 to $51 \% \mathrm{RH}$. However, due to the lower ERH of $\mathrm{MgCl}_{2}$ (lower than 2\%)
[43-45], water might be retained in the salt particles and pitting corrosion cannot be completely inhibited. That is to say, as the corrosion progressed, the pits formed on specimens under $\mathrm{MgCl}_{2}$ deposit condition would become deeper and wider during both the dry and wet stages, which also explains why stainless steels exposed to a salt lake atmosphere rich in $\mathrm{MgCl}_{2}$ with relatively lower humidity may suffer from severe pitting corrosion. In addition, the fluctuations in RH under periodic wet-dry cycle condition used to simulate the actual salt lake atmosphere might be favorable 

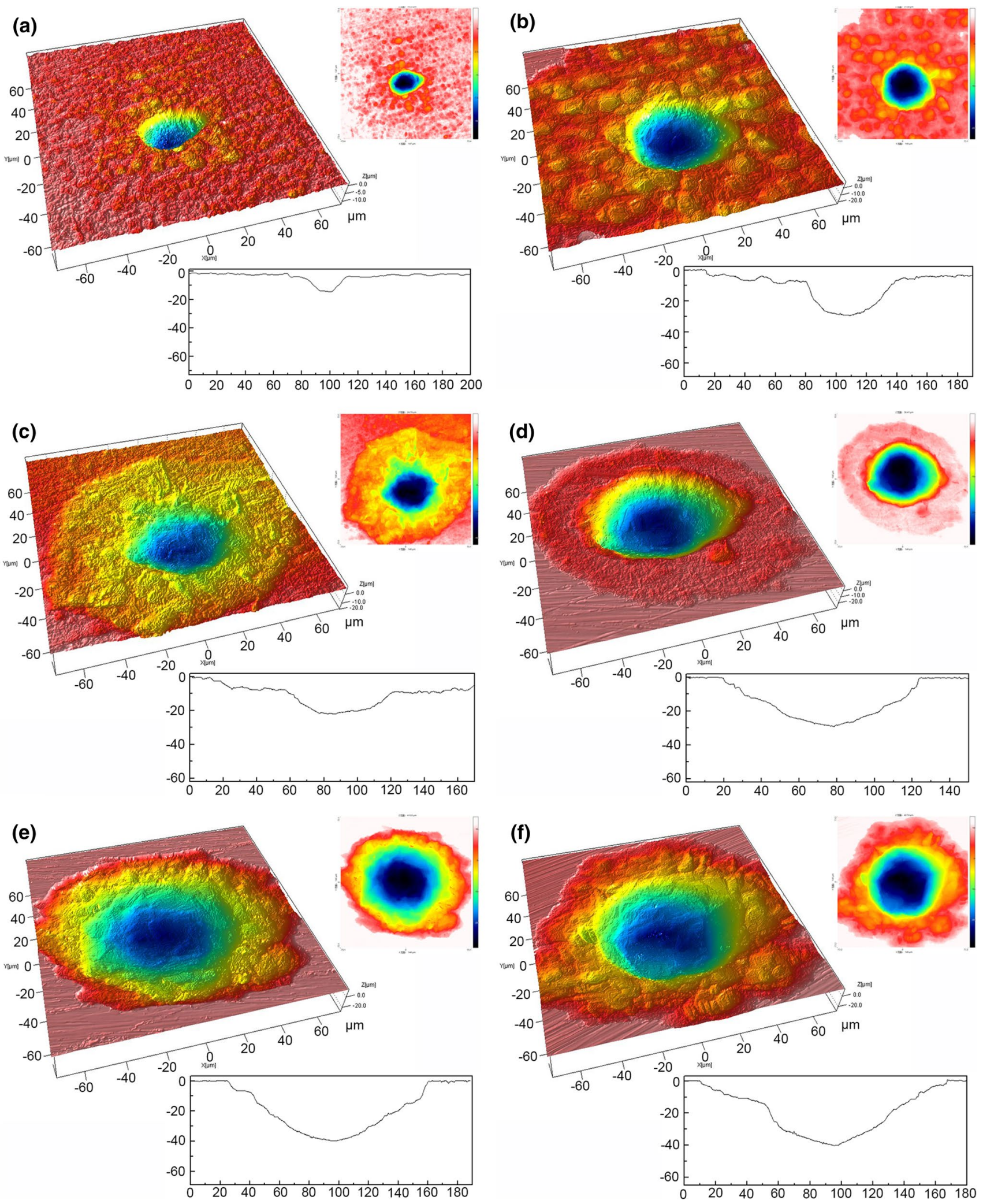

Fig. 10 Evolution of the 3D micro-morphologies for the naked white pits after removing the products of 304 stainless steel under $\mathrm{MgCl}_{2} \mathrm{deposit}$ condition for a 10 days, b 20 days, $\mathbf{c} 30$ days, $\mathbf{d} 40$ days, e 50 days, $\mathbf{f} 60$ days 


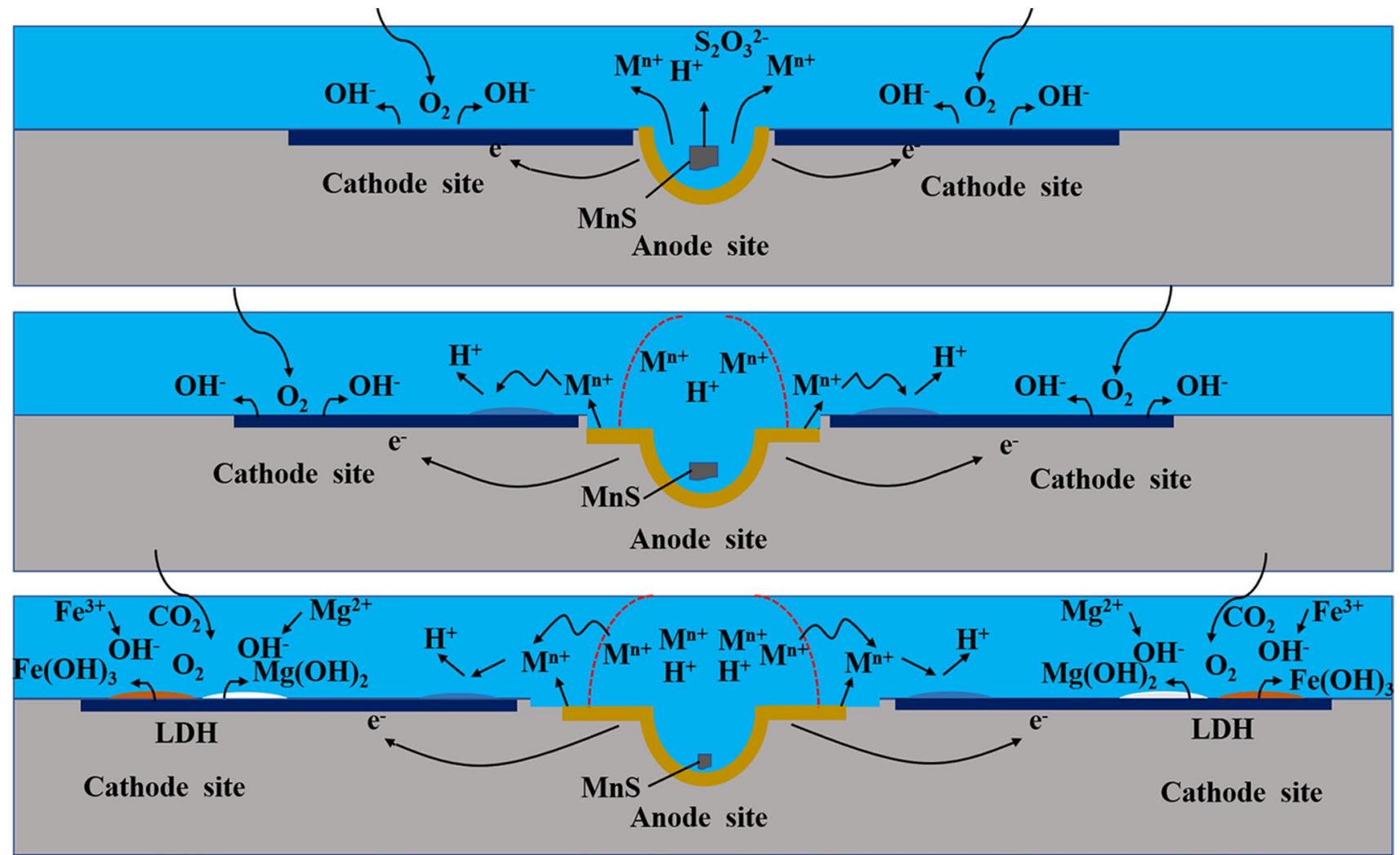

Fig. 11 Schematic of pitting corrosion mechanism of 304 stainless steel under $\mathrm{MgCl}_{2}$ deposit condition

for the formation of a large number of small pits rather than the growth of large penetrating pits [22].

\subsection{Effect of $\mathrm{MgCl}_{2}$ on the Corrosion Behavior of 304 Stainless Steel Exposed to a Simulated Salt Lake Atmosphere}

As shown in Fig. 8b, the typical pits with a yellowish concentric circle around the corroded area can be observed on stainless steel exposed to $\mathrm{MgCl}_{2}$ deposit condition in the constant humidity test. To better understand the composition and formation process of the yellowish concentric circle, EMPA was employed to analyze the distribution of foreign elements in the corrosion products, and the results are shown in Fig. 9. It can be seen that $\mathrm{Mg}$ was mainly distributed in the inner concentric ring, while the concentrations of $\mathrm{Cl}$ and $\mathrm{O}$ in the outer concentric ring were greater than those in the inner concentric ring, i.e., $\mathrm{Mg}$-containing corrosion products preferentially formed in the inner concentric ring.

In order to illustrate the micro-morphology of the naked white pits (shown in Fig. 2) formed under $\mathrm{MgCl}_{2}$ deposit condition, a white-light interferometer was employed to measure pit geometry. Figure 10 shows the evolution of 3D micro-morphologies for the naked white pits as a function of corrosion time after removing the products formed on
304 stainless steel exposed to $\mathrm{MgCl}_{2}$ deposit condition. As can be seen from these figures, there was always one significant pit in the center of the corroded area. Before 20 days of corrosion, most pits showed the "satellite" morphology (Fig. 10a, b), with several satellite-like pits at the perimeter of the significant pit or nearby. After 20 days of corrosion, there were no more pits with satellite-like shapes, and instead, deeper pits were formed (Fig. 10c-f). The changes in pit morphologies are closely related to the higher CDD, which increased with increasing corrosion time, leading to changes in the IR between the anode and cathode area and the ionic conductivity and diffusivity of highly concentrated solutions [18].

Based on the above analysis, it can be concluded that $\mathrm{MgCl}_{2}$ plays an important role in the corrosion process of stainless steels in a simulated salt lake atmosphere. Figure 11 shows the schematic of the pitting corrosion of stainless steels under $\mathrm{MgCl}_{2}$ deposit condition. This corrosion process can be illustrated as follows: a pit initiated at the $\mathrm{MnS}$ inclusion. The dissolution of $\mathrm{MnS}$ decreased the $\mathrm{pH}$ in the vicinity of the MnS inclusion in the presence of $\mathrm{Cl}^{-}$, resulting in the dissolution of the metal ions $(\mathrm{Fe}, \mathrm{Cr}, \mathrm{Ni})$ and then the occurrence of pits [46-48]. Some of the dissolved metal ions became hydrated, further decreasing the $\mathrm{pH}$. The remaining metal ions diffused and migrated outwards 


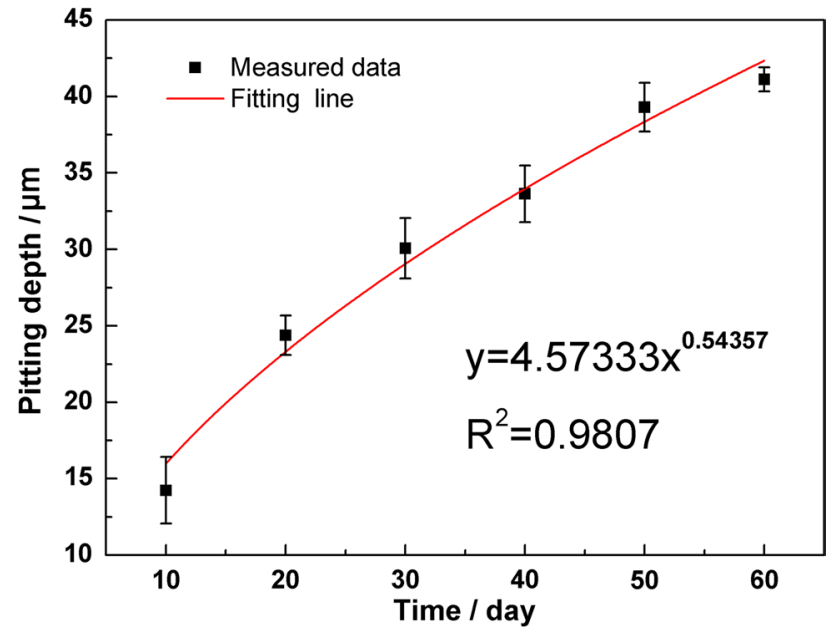

Fig. 12 Maximum pits depth of the 304 stainless steel under $\mathrm{MgCl}_{2}$ deposit condition as a function of corrosion time

through the thin solution layer, and some of them lowered the $\mathrm{pH}$ of the surroundings by the following hydrolysis reaction. However, the existence of $\mathrm{Mg}^{2+}$ could inhibit the diffusion and migration of $\mathrm{OH}^{-}$to the anode region because of the formation and deposition of $\mathrm{Mg}(\mathrm{OH})_{2}$. Therefore, the diffusion and migration of the metal cations to the cathode region was improved, and the hydrolysis reaction of these metal ions decreased the $\mathrm{pH}$ of the surroundings, resulting in an increase in the corroded area. Meanwhile, metal ions that diffused and migrated near the cathode precipitated as their hydroxides or oxides at a place where the $\mathrm{pH}$ was high enough to allow precipitation. Then, as the corrosion time increased some complex reactions between $\mathrm{Fe}(\mathrm{OH})_{3}$ and $\mathrm{Mg}(\mathrm{OH})_{2}$ would occur to form LDH [16, 30].

It is agreed that the maximum pit depth formed on the surface of stainless steel is closely related to the safety of stainless steel in service [49]. Therefore, statistical analysis was carried out to analyze the relationship between the maximum pit depth and the corrosion time. Figure 12 presents the evolution of the largest pit depth formed on the specimens as a function of corrosion time. The maximum pit depth increased gradually with increasing corrosion time. The depth of pits formed on the specimens after 10 days of corrosion was about $14 \mu \mathrm{m}$, whereas the pit depth formed after 60 days of corrosion was about $43 \mu \mathrm{m}$. According to the corresponding fitting results, it can be seen that the maximum pitting depth follows a power function with respect to the increase in corrosion time; $n<1$ indicates that the growth of pits in the initial stage was fast, and the rate of increase in the pit depth decreased as corrosion time progressed, which is consistent with the corrosion rate characterized by $1 / R_{\mathrm{ct}}$.

\section{Conclusion}

The corrosion behaviors of 304 stainless steel subjected to a simulated salt lake atmosphere were investigated. The experimental results indicated that a special corrosion product- $\left(\mathrm{Mg}_{6} \mathrm{Fe}_{2}(\mathrm{OH})_{16}\left(\mathrm{CO}_{3}\right)\left(\mathrm{H}_{2} \mathrm{O}\right)_{4.5}\right)_{0.25}$-was firstly detected on the stainless steel samples. During the wet stage and the dry stage of periodic wet-dry cycle condition used to simulate the actual salt lake atmosphere, the specimen exposed to $\mathrm{MgCl}_{2}$ deposit condition was corroded more severely than that exposed to $\mathrm{NaCl}$ deposit condition, because the ERH and DRH of $\mathrm{MgCl}_{2}$ were lower than those of $\mathrm{NaCl}$. Besides, the fluctuations in $\mathrm{RH}$ might be favorable to the formation of a large number of small pits. The shape of pits formed under $\mathrm{MgCl}_{2}$ deposit condition displayed a special corrosion morphology with a yellowish and concentric circle due to the inhibition of diffusion and migration of $\mathrm{OH}^{-}$ions to the anode region during the corrosion process. The maximum pit depth of 304 stainless steel increased with time according to a power function. The periodic wet-dry cyclic accelerated testing method adopted in this study is useful for the rapid assessment of the corrosion of stainless steel outdoor structures in a salt lake atmospheric environment.

Acknowledgements This work is supported by the National Natural Science Foundation of China (Nos. 51601199 and 51671197) and by the Guangzhou Industry-university-research Collaborative Innovation Alliance Special Project (201604046014).

\section{References}

[1] H.P. Leckie, H.H. Uhlig, J. Electrochem. Soc. 113, 1262 (1966)

[2] N.J. Laycock, R.C. Newman, Corros. Sci. 39, 1771 (1997)

[3] R.H. Jung, H. Tsuchiya, S. Fujimoto, Corros. Sci. 58, 62 (2012)

[4] D. Wallinder, I.O. Wallinder, C. Leygraf, Corrosion 59, 220 (2003)

[5] C. Pan, W.Y. Lv, Z.Y. Wang, W. Su, C. Wang, S.N. Liu, J. Mater. Sci. Technol. 33, 83 (2017)

[6] C.F. Liang, C.J. Yu, W.T. Hou, J. Chin. Soc. Corros. Prot. 19, 36 (1999)

[7] Y. Tsutsumi, A. Nishikata, T. Tsuru, Corros. Sci. 49, 1394 (2007)

[8] Q. Yin, Z.Y. Wang, M.R. Liu, C. Pan, Acta Metall. Sin. (Engl. Lett.) 32, 780 (2019)

[9] M.R. Liu, X. Lu, Q. Yin, C. Pan, C. Wang, Z.Y. Wang, Acta Metall. Sin. (Engl. Lett.) 32, 995 (2019)

[10] M.X. Guo, C. Pan, Z.Y. Wang, W. Han, Acta Metall. Sin. 54, 65 (2018). (in Chinese)

[11] Z.Y. Wang, G.C. Yu, W. Han, J. Chin. Soc. Corros. Prot. 24, 323 (2003)

[12] M.P. Zheng, Foreign Depos. Geol. 3, 1 (1989)

[13] M.P. Zheng, X.F. Liu, Acta Geol. Sin. 84, 1585 (2010) 
[14] Y.D. Xiao, G.Z. Wang, X.G. Li, A. Lin, S.P. Zhang, X.Z. Qin, Z.Y. Wang, C.F. Liang, Q.F. Zheng, H.R. Mao, J. Chin. Soc. Corros. Prot. 23, 248 (2003)

[15] J. Wang, Z.Y. Wang, W. Ke, Corros. Eng., Sci. Technol. 47, 125 (2012)

[16] B.B. Wang, Z.Y. Wang, W. Han, W. Ke, Corros. Sci. 59, 63 (2012)

[17] J. Wang, Z.Y. Wang, W. Ke, Mater. Chem. Phys. 139, 225 (2013)

[18] S.R. Street, N. Mi, A.J. Cook, H.B. Mohammed-Ali, L. Guo, T. Rayment, A.J. Davenport, Faraday Discuss. 180, 251 (2015)

[19] T. Tsuru, A. Nishikata, J. Wang, Mater. Sci. Eng., A 198, 161 (1995)

[20] A. Nishikata, Y. Yamashita, H. Katayama, T. Tsuru, A. Usami, Corros. Sci. 37, 2059 (1995)

[21] T.V. Nam, E. Tada, A. Nishikata, J. Electrochem. Soc. 162, 419 (2015)

[22] L.Y. Guo, S.R. Street, H.B. Mohammed-Ali, M. Ghahari, N. Mi, S. Glanvill, A. Du Plessis, C. Reinhard, T. Rayment, A.J. Davenport, Corros. Sci. 150, 110 (2019)

[23] C.Q. Cheng, L.I. Klinkenberg, Y. Ise, J. Zhao, E. Tada, A. Nishikata, Corros. Sci. 118, 217 (2017)

[24] B. Maier, G.S. Frankel, J. Electrochem. Soc. 157, 302 (2010)

[25] S. Hastuty, A. Nishikata, T. Tsuru, Corros. Sci. 52, 2035 (2010)

[26] E. Schindelholz, R.G. Kelly, I.S. Cole, W.D. Ganther, T.H. Muster, Corros. Sci. 67, 233 (2013)

[27] W. Han, G.C. Yu, Z.Y. Wang, J. Wang, Corros. Sci. 49, 2920 (2007)

[28] S. Liu, H. Sun, L.J. Sun, H.J. Fan, Corros. Sci. 65, 520 (2012)

[29] I.M. Ahmed, M.S. Gasser, Appl. Surf. Sci. 259, 650 (2012)

[30] G.G. Gou, P.H. Ma, Acta Phys.-Chim. Sin. 20, 1357 (2004)
[31] S. Musić, S. Krehula, S. Popović, Mater. Lett. 58, 444 (2004)

[32] V.R.L. Constantino, T.J. Pinnavaia, Inorg. Chem. 34, 883 (1995)

[33] K.P. Wong, R.C. Alkire, J. Electrochem. Soc. 137, 3010 (1990)

[34] J.O. Park, C.H. Paik, Y.H. Huang, R.C. Alkire, J. Electrochem. Soc. 146, 517 (1999)

[35] W.J. Lorenz, F. Mansfeld, Corros. Sci. 21, 647 (1981)

[36] M. Itagaki, R. Nozue, K. Watanabe, H. Katayama, K. Noda, Corros. Sci. 46, 1301 (2004)

[37] K.W. Chung, K.B. Kim, Corros. Sci. 42, 517 (2000)

[38] M.C. Yan, C. Sun, J. Xu, W. Ke, Ind. Eng. Chem. Res. 53, 17615 (2014)

[39] Y.L. Cheng, Z. Zhang, F.H. Cao, J.F. Li, J.Q. Zhang, J.M. Wang, C.N. Cao, Corros. Sci. 46, 1649 (2004)

[40] E. Schindelholz, B.E. Risteen, R.G. Kelly, J. Electrochem. Soc. 161, $460(2014)$

[41] Z.Y. Chen, F. Cui, R.G. Kelly, J. Electrochem. Soc. 155, 360 (2008)

[42] R.P. Vera Cruz, A. Nishikata, T. Tsuru, Corros. Sci. 38, 1397 (1996)

[43] D.J. Cziczo, J.P.D. Abbatt, J. Phys. Chem. A 104, 2038 (2007)

[44] Y. Gao, S.B. Chen, L.E. Yu, Atmos. Environ. 41, 2019 (2007)

[45] D.D. Weis, G.E. Ewing, J. Geophys. Res.-Atmos. 104, 21275 (1999)

[46] C. Pan, L. Liu, Y. Li, F.H. Wang, Corros. Sci. 73, 32 (2013)

[47] P. Schmuki, H. Hildebrand, A. Friedrich, S. Virtanen, Corros. Sci. 47, 1239 (2005)

[48] S.J. Zheng, Y.J. Wang, B. Zhang, Y.L. Zhu, C. Liu, P. Hu, X.L. Ma, Acta Mater. 58, 5070 (2010)

[49] W.Y. Lv, C. Pan, W. Su, Z.Y. Wang, S.N. Liu, C. Wang, J. Mater. Eng. Perform. 24, 2597 (2015) 